\title{
Buyer power of retailers with limited selling capacity*
}

\author{
Ramon Fauli-Oller (University of Alicante) $)^{\dagger}$
}

30th of May 2020

\begin{abstract}
We have two upstream firms producing each one a different good. Demands of the goods are independent, symmetric and linear. Goods are sold to consumers through retailers. The units of both goods sold by retailers cannot exceed the industry selling capacity that it is distributed symmetrically among retailers. Taking as given the industry selling capacity, when the number of retailers decreases, they become bigger in the sense that their selling capacity increases. Therefore, changing the number of retailers, we can check whether the countervailing power theory, that states that bigger retailers obtain better deals from suppliers, holds in our model. We obtain that the lower the number of retailers, the lower the wholesale prices, only when the industry selling capacity is high.

JEL Classification: L13;L41;L42

keywords: retailing, mergers, selling capacity
\end{abstract}

\footnotetext{
*I acknowledge financial support from the Spanish Ministerio de Economía y Competitividad and FEDER funds ECO2015-65820-P (MINECO/FEDER) and from Generalitat Valenciana grant PROMETEO/2019/037. I thank Miguel González-Maestre, Joel Sandonís and Luis Ubeda for helpful comments that have allowed me to improve the paper. Thanks are also due to the Editor Kevin Amess and to an anonymous referee for their helpful suggestions. I am also grateful to seminar audiences in Universitat de València and University of Alicante. The usual disclaimer applies. Part of this research was written while I was visiting the Institut d'Anàlisi Econòmica (CSIC).

†Fundamentos del Análisis Económico (FAE), Universidad de Alicante, Campus de Sant Vicent del Raspeig, E-03071, Alicante, Spain. E-mail address: fauli@ua.es.
} 


\section{Introduction}

Concentration in a market is usually associated with high prices. However, the theory of countervailing power, first proposed by Galbraith (1952), argues that a concentrated retail market can have a positive effect on prices, because then retailers are larger and this allows them to countervail the power of producers and obtain better deals from them. If these better deals are passed on to the consumers in the form of lower final prices, higher levels of concentration in the retail sector will be associated with lower final prices.

The theory of countervailing power has had a lot of influence and even the competition authorities in both Europe and the United States recognize that a concentrated downstream sector limits the anti-competitive effects of upstream mergers. ${ }^{1}$ However, within the framework considered in this article, characterized by linear supply contracts, theoretical studies do not give a conclusive answer (Von Ungern-Sternberg (1996), Dobson and Waterson (1997), Tyagi (1999), Iozzi and Valetti (2014), Gaudin (2018). For example, Tyagi (1999), which is the closest to our analysis because it considers competition à la Cournot and a wholesale price set by the producer, obtains that the wholesale price does not depend on the level of concentration of the retail sector for the most common demands including linear and constant elasticity demands.

Unlike the cited articles, we consider the case in which retailers are capacity constraint. We find many cases in the literature where retailers are capacity constraint. For example, when a retailer invokes an exclusive dealing clause is as if it restricted its capacity to accommodate only one good (Gabrielsen and Sorgard (1999)). O'Brien and Shaffer (1997) obtain that a retailer has incentives to limit her shelf space in order to reduce the number of goods she can sell. Shaffer (1991), Moner-Colonques (2006) and Inderst and Shaffer (2007) consider that shelf space is scarce and therefore retailers can not sell all the available goods.

In all those papers, the restriction on capacity affects the number of goods the retailer can sell. Instead, in our case, capacity will put a limit on the units of the goods the retailer can sell. The following quotation explains the difference between the two approaches. "We have in mind a situation in which each good requires a minimum amount of shelf space (at least one shelf facing) for display to consumers. In that case, it is the width of the shelf space that matters, and not the depth, as units of the same good can be stacked one behind the other". (O'Brien and Shaffer (1997) p. 774). So far, papers have put the emphasis on the width of the shelf space, whereas, in our case, it is the depth of the shelf space that matters.

The importance of the depth of the shelf space has long been recognized by the literature on multi-item newsvendor problems with capacity constraints.

${ }^{1}$ For example, although the expected market share of the Ensor / Stora merger was between 50 and $70 \%$ in the market of Liquid Packaging Board (LPB), the merger was cleared by the European Commission because between 60 and $80 \%$ of the purchases were concentrated in a single company, Tetrapak. (Motta(2006) p.122) 
The following quotation clarifies the issue: "The second problem that commonly faces manufacturers, distributors, and retailers is determining how much capacity of a certain resource (e.g., budget, shelf space, time) to allocate to one activity when other activities are competing for that resource. For example, a clothing retailer may have only a limited amount of shelf space to devote to several sizes or styles of a certain good, such as sweaters. Given the variety of sizes and styles of sweaters that the retailer sells, it is not obvious how much shelf space should be devoted to each style and size given limited shelf space". (Erlebacher (2000) p. 303)

In the present model, we have two firms that produce each one a different good. Demands of the goods are independent, symmetric and linear. Goods are sold to consumers through retailers. Trade between manufacturers and retailers takes place through linear supply contracts chosen by suppliers. The units of both goods sold by retailers cannot exceed the industry selling capacity that it is distributed symmetrically among retailers. We perform the following comparative statics analysis. We keep constant the industry selling capacity and we allow the number of symmetric retailers to vary to see its influence on equilibrium wholesale prices. This allows us to assess the validity of the countervailing power theory, because the lower the number of retailers the bigger their size measured by their selling capacity and higher the concentration.

The results I obtain depend on the market structure upstream. An upstream monopoly will set the same wholesale price for each good that satisfies that it is the highest one such that retailers sell up to capacity. When the number of retailers increases, the upstream monopoly will raise the wholesale price up to the point that retailers still sell up to capacity. It is similar to what happens in a competitive market with a perfectly inelastic supply when demand increases: sales remain constant but price increases.

With multiple upstream firms and low enough industry capacity, retailers are capacity constrained i.e. they would like to sell more than their capacity. In this case, the demand of goods become interdependent in the sense that an upstream firm by lowering the wholesale price increases its sales and reduces the sales of the competitor. It turns out that the demand of retailers of each good becomes more elastic as the number of retailers increases. Therefore, the higher the number of retailers, the more profitable is for the suppliers to reduce the wholesale prices because sales increase by more. This explains that equilibrium wholesale prices decrease with the number of retailers, which contradicts the countervailing power theory.

As far as retail prices are concerned, we never obtain that an increase in concentration in the retailing sector reduces retail prices. If industry capacity is large, retailers are not capacity constraint and the two markets are completely separated. Then, Tyagi (1999) applies and the wholesale price is independent of the number of retailers and retail price is decreasing in the number of retailers. If industry capacity is small, then retailers are capacity constrained both before and after the change in the level of concentration. Therefore, in any case, retailers sell up to capacity and the retail prices are constant. The change in the wholesale prices only affects the division of rents between retailers and 
suppliers. The most interesting result is obtained for intermediate values of the industry capacity. In this case, retailers are capacity constrained before the change in concentration but they are not capacity constrained when concentration increases. Then, the increase in concentration reduces wholesale prices but increases retail prices.

In the second part of the paper, we contribute to the debate on the effect of downstream mergers over buyer power. Many different reasons have been provided by the literature to explain why size obtained through merger can allow retailers to obtain better deals from suppliers. For example, Katz (1987) and Inderst and Wey (2011) suppose that buyers, by investing a fixed cost, can integrate backwards to produce the good sold by suppliers. This possibility is more profitable and therefore it allows the buyer to obtain better deals from suppliers, the larger the size of the buyer, because then it can spread this fixed cost over a larger production. Chipty and Snyder (1999) study the case where one supplier sells an homogeneous good to a given number of retailers that are monopolists in their local markets. Then, the merger of retailers does not change the quantities sold in each local market but it affects the marginal contribution of each retailer to industry profits. This contribution increases more than proportionally with the quantity traded when the unit cost of the supplier is increasing. Then the merger of retailers is profitable. In Snyder (1996) greater size can allow retailers to break collusion among suppliers.

Next, keeping constant the industry selling capacity, we study the merger of all retailers. With monopoly upstream we obtain that the merger is always profitable. With multiple upstream firms, the profitability of the merger depends on its effect on wholesale prices. For low capacity levels, we obtain that wholesale prices increase with the merger and therefore the merger of retailers is not profitable. For high capacity levels, instead, wholesale prices decrease with the merger and the merger is profitable.

For low capacity levels, we obtain an interesting relationship between market structure upstream and market structure downstream. The upstream merger makes profitable the downstream merger. This is consistent with the empirical evidence provided by Kastrinaki and Stoneman (2011) when they state that "[w]e thus have evidence for all the studied countries, except the Netherlands, that merger activity in manufacturing has led to merger activity in retailing" p. 476 .

In the next Section, we set up the model and study the relationship between the size of retailers and wholesale prices. In Section 3, we study the profitability of the merger of all retailers and relate it to the market structure upstream. In the last Section, final comments put the paper to an end.

\section{Model}

Assume we have two producers (1 and 2). Producer 1 (2) produces good 1 (2). Goods 1 and 2 are independent. Inverse demand of good $i(i=1,2)$ is given 
by $P_{i}=a-Q_{i}$, where $P_{i}$ and $Q_{i}$ are respectively the price and the quantity sold of good $i$. Upstream firms sell the goods through symmetric retailers. Retailers transform one unit bought to the upstream firm into one unit sold to final consumers. There are $n$ retailers. Each retailer is denoted with a natural number from 1 to $n$. The distinguishing characteristic of each retailer is that it has a limited shelf space. In particular, we assume that the total units of the two goods that she can sell is lower than $\frac{X}{n}$. In particular, if $x_{i}^{j}$ denotes the quantity that the retailer $j$ sells of good $i$, we must have that $x_{1}^{j}+x_{2}^{j} \leq \frac{X}{n}$. For both upstream and downstream firms, all other costs are constant (with loss of generality) and normalized to zero (with no loss of generality).

We analyze the following two stage game. In the first stage, producer $i$ $(i=1,2)$ chooses its wholesale price $w_{i} \leq a$. In the second stage, retailers compete à la Cournot taking into account that for all $j$ we must have that $x_{1}^{j}+x_{2}^{j} \leq \frac{X}{n}$. As a matter of comparison, we will also consider the case where producer 1 and 2 have merged (upstream monopoly).

\subsection{Second stage}

It is well-known that, without selling capacity constraints, each retailer would sell $x_{1}^{j}=\frac{a-w_{1}}{n+1}$ and $x_{2}^{j}=\frac{a-w_{2}}{n+1}$. Then those will be the sales in equilibrium when

$$
\frac{a-w_{1}}{n+1}+\frac{a-w_{2}}{n+1}=\frac{2 a-w_{1}-w_{2}}{n+1} \leq \frac{X}{n}
$$

When this constraint is satisfied we say that we are in Region 1 . If we are not in Region 1, we are in Region 2, where retailers sell up to capacity. Then, the maximization program of the retailer $j$ is:

$$
\begin{aligned}
& { }_{x_{1}^{j}}^{\operatorname{Max}}\left(a-x_{1}^{j}-\sum_{k \neq j} x_{1}^{k}-w_{1}\right) x_{1}^{j}+\left(a-\left(\frac{X}{n}-x_{1}^{j}\right)-\sum_{k \neq j}\left(\frac{X}{n}-x_{1}^{k}\right)-w_{2}\right)\left(\frac{X}{n}-x_{1}^{j}\right) \\
\text { s.t.0 } \leq & x_{1}^{j} \leq \frac{X}{n}
\end{aligned}
$$

The equilibrium of this game where retailers play up to capacity is the following:

$$
\begin{aligned}
& x_{1}^{j}=\frac{-w_{1}+w_{2}+X\left(\frac{n+1}{n}\right)}{2(n+1)} \text { and } x_{2}^{j}=\frac{-w_{2}+w_{1}+X\left(\frac{n+1}{n}\right)}{2(n+1)} \text { if }-w_{1}+w_{2}+ \\
& X\left(\frac{n+1}{n}\right)>0 \text { and }-w_{2}+w_{1}+X\left(\frac{n+1}{n}\right)>0 \\
& (\text { Region 2i). } \\
& x_{1}^{j}=\frac{X}{n} \text { and } x_{2}^{j}=0 \text { if }-w_{2}+w_{1}+X\left(\frac{n+1}{n}\right) \leq 0 \text { (Region 2ii) } \\
& x_{1}^{j}=0 \text { and } x_{2}^{j}=\frac{X}{n} \text { if }-w_{1}+w_{2}+X\left(\frac{n+1}{n}\right) \leq 0 \text { (Region 2iii). } \\
& \text { The four Regions are depicted in Figure 1: }
\end{aligned}
$$






Figure 1: Second stage equilibrium.

The sales of good $i$ in Region $2 \mathrm{i}$ are increasing in the capacity $X$ and increasing in the wholesale price $w_{j}$, whereas, in Region 1 , the sales of good $i$ do not depend neither in $X$ nor in $w_{j}$. The reason for this difference is that in Region $2 \mathrm{i}$, retailers are capacity constrained (i.e. they would like to sell a quantity of both goods higher than their capacity), whereas in Region 1 they are not. The fact that, in Region 2i, demands are interdependent (goods behave as if they were gross substitutes) is at first sight surprising because goods are independent, but this is explained by the fact that retailers are capacity constrained.

\section{$2.2 \quad$ First stage}

Without selling capacity constraints, the equilibrium wholesale prices are given by $w_{1}^{*}=w_{2}^{*}=\frac{a}{2}$ and retailers sell $x_{i}^{j}=\frac{a}{2(n+1)}$. If $\frac{a}{(n+1)} \leq \frac{X}{n}$, this will still be the equilibrium of the present game, because deviation profits can not increase with the presence of selling capacity constraints. Then, wholesale prices do not depend on the number of retailers. Profits of the upstream firms are given by $\frac{a^{2} n}{2(n+1)}$. They are increasing in $n$. Retail prices are decreasing in $n$.

Next, we solve the model for the case $X<\frac{a n}{(n+1)} .{ }^{2}$ First we consider the

\footnotetext{
${ }^{2}$ In Figure 1 we have that $\frac{X(n+1)}{n}<a$. Rearranging terms we have $X<\frac{a n}{(n+1)}$ that it is the condition we assume to hold in the discussion that follows.
} 
case where producer 1 and 2 have merged (upstream monopoly) and then the case where producer 1 and 2 are independent firms (multiple upstream firms).

\subsubsection{Upstream monopoly}

It is very easy to derive the optimal wholesale prices (for a formal proof see Appendix 1). The merged firm will set the same wholesale price $w^{*}$ for each good that satisfies that it is the highest wholesale price such that retailers sell up to capacity.

$$
\begin{aligned}
2\left(\frac{a-w^{*}}{n+1}\right) & =\frac{X}{n} \\
w^{*} & =a-\frac{(n+1) X}{2 n}>\frac{a}{2}
\end{aligned}
$$

Proposition 1 summarizes:

Proposition 1 The equilibrium wholesale prices with monopoly upstream are given by $w_{1}^{*}=w_{2}^{*}=a-\frac{(n+1) X}{2 n}$ if $0<X<\frac{a n}{n+1}$.

We have that $w_{i}^{*}$ decreases with $X$ and increases with $n$. The main purpose of the paper is to check whether big retailers receive discounts from suppliers. Given that retailers are symmetric, their size decreases with the number of firms. Next proposition compares wholesale prices for different values of the number of retailers.

Proposition 2 With monopoly upstream, the wholesale prices with $n_{1}$ retailers are lower than the wholesale prices with $n_{2}$ retailers if $n_{1}<n_{2}$.

Therefore the countervailing power theory holds: the bigger the retailers the lower the wholesale prices. However, this reduction in the wholesale prices when concentration increases is not passed on to the consumers in the form of lower retail prices. For $X \leq \frac{a n_{1}}{n_{1}+1}$, the reduction in the number of retailers, reduces the wholesale price but it does not affect the retail price, because in any case retailers sell up to capacity. Therefore, the reduction in the number of retailers only shifts rents from suppliers to retailers. For $\frac{a n_{1}}{n_{1}+1}<X<\frac{a n_{2}}{n_{2}+1}$, when the number of retailers decreases from $n_{2}$ to $n_{1}$ we have that the wholesale price decreases but the retail price increases. ${ }^{3}$ For $X \geq \frac{a n_{2}}{n_{2}+1}$, as indicated in

\footnotetext{
${ }^{3}$ For $n_{1}$ the wholesale price is $\frac{a}{2}$ (Section 2.2) and for $n_{2}$ is higher than $\frac{a}{2}$ (Section 2.2.1). The quantity sold in each market, with $n_{1}$, is $\frac{n_{1}\left(a-\frac{a}{2}\right)}{n_{1}+1}=\frac{a n_{1}}{2\left(n_{1}+1\right)}$ and the quantity sold in each market with $n_{2}$, given that retailers sell up to capacity is $\frac{X}{2}$. Given the assumption, the former expression is smaller than the latter and therefore the retail price is lower with $n_{2}$ than with $n_{1}$.
} 
Section 2.2 , the wholesale price is $\frac{a}{2}$ both for $n_{2}$ and $n_{1}$. Then, retail prices are lower with $n_{2}$, because competition is stronger.

\subsubsection{Multiple upstream firms}

In order to obtain the equilibrium of the first stage, we compute the best response function of producer 1 (the one of producer 2 is symmetric), whose actual shape is stated in Appendix 2. To understand it we are going to show how the profit of firm 1 changes as $w_{1}$ changes, taking as given $w_{2}$ and $X$. Although in Figure 1 we have 4 different regions ${ }^{4}$, we focus on what happens in Region 2i and Region 1. As it can be checked in Figure 1, for low values of $w_{1}$ we are in Region $2 \mathrm{i}$ and for high values of $w_{1}$, we are in Region 1 . The profit of firm 1 is continuous and strictly concave both in Region $2 \mathrm{i}$ and Region 1, but it has a kink in $\bar{w}_{I}=2 a-\frac{(n+1)}{n} X-w_{2}$, the wholesale price that separates Region 2i from Region 1. Therefore, depending on the parameters the optimal choice for firm 1 may lie in Region 2i, in Region 1 or in $\bar{w}_{I}$. This explains that the best response of firm 1 in the first stage is divided in different parts. Given $X$, this best response function crosses the 45 degree line only once. This crossing point determines the equilibrium in wholesale prices that is stated in proposition 3 .

Proposition 3 The equilibrium wholesale prices with multiple upstream firms are given by $w_{1}^{*}=w_{2}^{*}=\frac{(n+1) X}{n}$ if $0 \leq X<\frac{2 a n}{3(n+1)}$ and $w_{1}^{*}=w_{2}^{*}=$ $a-\frac{(n+1) X}{2 n}$ if $\frac{2 a n}{3(n+1)} \leq X<\frac{a n}{n+1}$.

Wholesale prices are the same with multiple upstream firms as with monopoly upstream if selling capacity is high. Multiple upstream firms have an effect only when selling capacity is significantly scarce i.e. $X<\frac{2 a n}{3(n+1)}$. In this case, wholesale prices are higher with monopoly upstream than with multiple upstream firms. Therefore, the existence of multiple upstream firms (weakly) reduces wholesale prices. This result corresponds to the one obtained, among others, by Horn and Wolinsky (1988), Iozzi and Valetti (2014) and Milliou and Sandonís (2018).

Figure 2 plots the equilibrium wholesale prices as a function of capacity $(X)$ for the case $n=3$ and $n=15$ (bold line) setting $a=1$. They are increasing for low capacities and decreasing for high capacities. In the former case, we are in Region $2 \mathrm{i}$ where retailers are capacity constrained. They would like to

\footnotetext{
${ }^{4}$ The equilibrium can not lie neither in Region 2ii nor in Region 2iii. In Region 2ii firm 2 obtains zero profits because it sells nothing. It can increase its profits by lowering $w_{2}$ such that wholesale prices lie in Region 2i, where firm 2 makes positive sales. A symmetric argument holds for Region 2iii.
} 


\section{wholesale price}

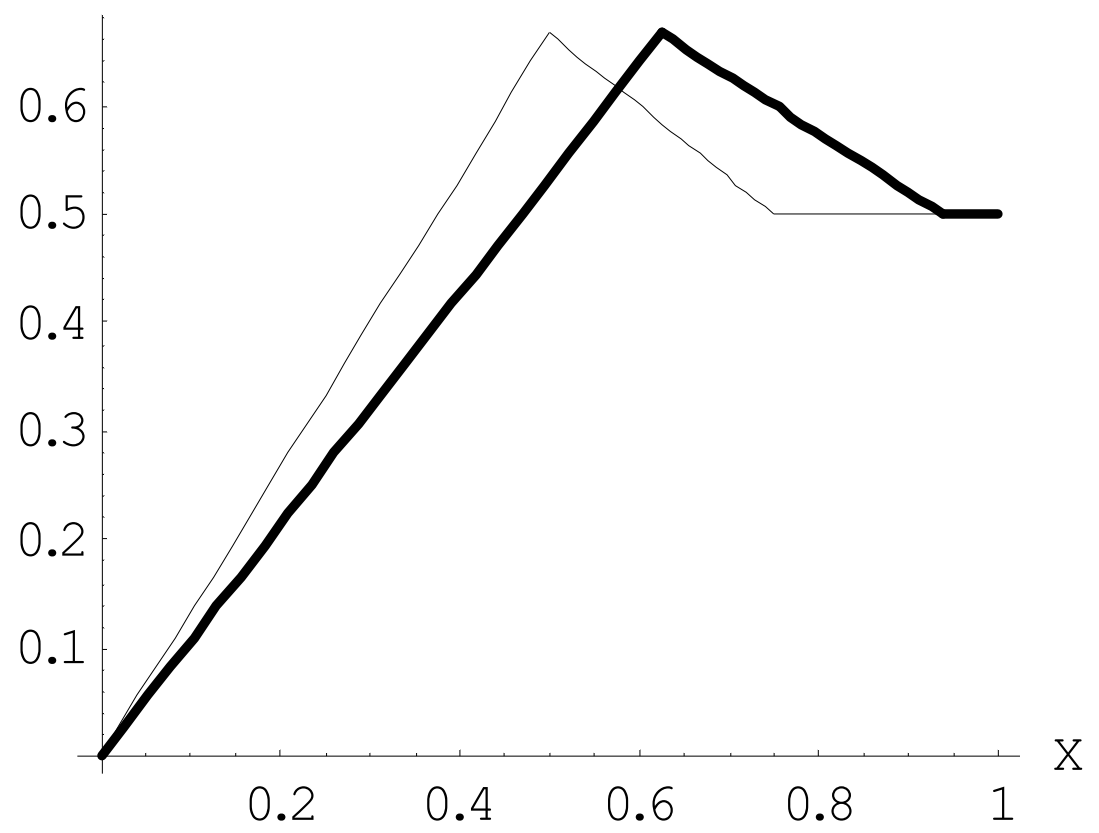

Figure 2: Equilibrium wholesale price.

sell more than the capacity they have. This implies that their sales increase with capacity. Then, suppliers adjust their optimal wholesale prices upwards when industry capacity increases. On the contrary, when capacity is large, we are in the frontier between Region 1 and Region $2 \mathrm{i}$ where the unconstrained sales coincide with the capacity retailers have. Then, when capacity increases, wholesale prices should decrease to keep the equality between the unconstrained sales and capacity.

The main goal of the paper is to study how the number of retailers (i.e. their size) affect the equilibrium wholesale prices. Suppose that $n_{1}<n_{2}$. We want to know when the wholesale prices will be higher either when the number of retailers is $n_{1}$ or when the number of retailers is $n_{2}$. The countervailing power theory would suggest that wholesale prices should be higher with $n_{2}$ because then retailers are smaller. Next Proposition, proved in Appendix 3, shows that this is not always the case:

Proposition 4 With multiple upstream firms and $n_{1}<n_{2}$, wholesale prices with $n_{1}$ retailers are higher than the wholesale prices with $n_{2}$ retailers if $0<$ 
$X<\tilde{X}$ where $\tilde{X}=\frac{2 a n_{1} n_{2}}{2 n_{1}+n_{2}+3 n_{1} n_{2}}$. Wholesale prices with $n_{1}$ retailers are lower than the wholesale prices with $n_{2}$ retailers if $\tilde{X}<X<\frac{a n_{2}}{n_{2}+1}$.

We can check the result in Proposition 4 in Figure 2: the wholesale price for $n=15$ is lower than the wholesale price for $n=3$ for low capacities and higher for high capacities.

Countervailing power theory does not hold when capacity is low. It would be interesting to find an intuition for this result. When capacity is scarce, the equilibrium lies in the interior of Region $2 \mathrm{i}$. The demand of retailers of good $i$ in Region $2 \mathrm{i}$ is given by:

$$
X_{i}=\frac{n\left(-w_{i}+w_{j}\right)+(n+1) X}{2(n+1)}
$$

The elasticity of demand with respect to $w_{i}$ is given by:

$$
\varepsilon_{i}=\left|\frac{\partial X_{i}}{\partial w_{i}}\right| \frac{w_{i}}{X_{i}}=\frac{n w_{i}}{X+n\left(-w_{i}+w_{j}+X\right)}
$$

The previous expression is increasing in $n$. This means that the higher $n$, the more elastic the demand, and therefore the more profitable is to undercut the rival producer. This explains that the equilibrium wholesale price decreases with $n$.

To understand this counterintuitive result, that occurs in Region 2i, we are going to analyze two extreme cases. We are going to compare how a monopolist retailer $(n=1)$ and a competitive retailer $(n=\infty)$ adjust their sales when upstream firm $i$ decreases its wholesale price. The starting point is such that both producers set the same wholesale prices and therefore in both cases retailers sell of each good half of their capacity. Think that now upstream firm $i$ reduces its wholesale price. In the case of a competitive retailer the equilibrium condition implies that price margins should be equalized across markets. If $x_{i}^{C}$ are the sales of good $i$ and $x_{j}^{C}$ the sales of good $j$ of the competitive retailer after $w_{i}$ has decreased, we have:

$$
a-x_{i}^{C}-w_{i}=a-x_{j}^{C}-w_{j}
$$

As we are in Region $2 \mathrm{i}$ the retailer sells up to capacity and therefore $x_{j}^{C}=$ $X-x_{i}^{C}$. Then we have:

$$
a-x_{i}^{C}-w_{i}=a-\left(X-x_{i}^{C}\right)-w_{j}
$$

Solving for $x_{i}^{C}$ we obtain

$$
x_{i}^{C}=\frac{w_{j}-w_{i}+X}{2}
$$

A monopolist retailer, instead, will increase the sales of good i but not to the point to equalize margins, because as she sells more of good i she prefers to have 
a higher margin in good i. If $x_{i}^{M}$ are the sales of a monopolist retailer of good $i$ we have:

$$
\begin{aligned}
a-x_{i}^{M}-w_{i}> & a-\left(X-x_{i}^{M}\right)-w_{j} \\
& x_{i}^{M}<\frac{w_{j}-w_{i}+X}{2}
\end{aligned}
$$

This implies that the increase in the sales of good $i$ will be higher with the competitive retailer than with the monopolist retailer because:

$$
\frac{X}{2}<x_{i}^{M}<x_{i}^{C} .
$$

Then, producer $i$ will be more interested in cutting the wholesale price $w_{i}$ when she faces a competitive retailer than when she faces a monopolist retailer. Therefore, wholesale prices will be lower in the former case. The two extreme cases, we have analyzed, illustrate the general result that in Region $2 \mathrm{i}$ increasing competition downstream reduces wholesale prices, because it increases the incentives of suppliers to reduce their wholesale prices.

The evolution of retail prices is much simpler than the evolution of wholesale prices. For $X \leq \frac{a n_{1}}{n_{1}+1}$, the reduction in the number of retailers from $n_{2}$ to $n_{1}$ does not affect retail prices, because in any case retailers sell up to capacity. The changes in wholesale prices only affect how rents are shared between suppliers and retailers. For $X>\frac{a n_{1}}{n_{1}+1}$, the reduction in the number of retailers increases retail prices.

\section{Downstream mergers}

The industry downstream profits as a function of $X$ are given by:

$$
\Pi^{D}(n)=\left\{\begin{array}{lrl}
X\left(a-\frac{3 X}{2}-\frac{X}{n}\right) & \text { if } \quad 0 \leq X \leq \frac{2 a n}{3(n+1)} \\
\frac{X^{2}}{2 n} & \text { if } & \frac{2 a n}{3(n+1)}<X \leq \frac{a n}{n+1} \\
\frac{a^{2} n}{2(n+1)^{2}} & & \text { otherwise }
\end{array}\right.
$$

The typical shape of the industry profits downstream ${ }^{5}$ is presented in Figure 3.

It is concave for low capacities, then increasing and finally constant when retailers are unconstrained. The concave part reflects a trade-off. For low capacities, increasing capacity has the positive effect on profits of increasing sales but the negative effect of increasing the wholesale prices. The decreasing part of the function identifies a region where retailers would be better-off if they would agree collectively to restrict capacity.

\footnotetext{
${ }^{5}$ The actual picture is obtained by setting $a=1$ and $n=4$.
} 


\section{profits}

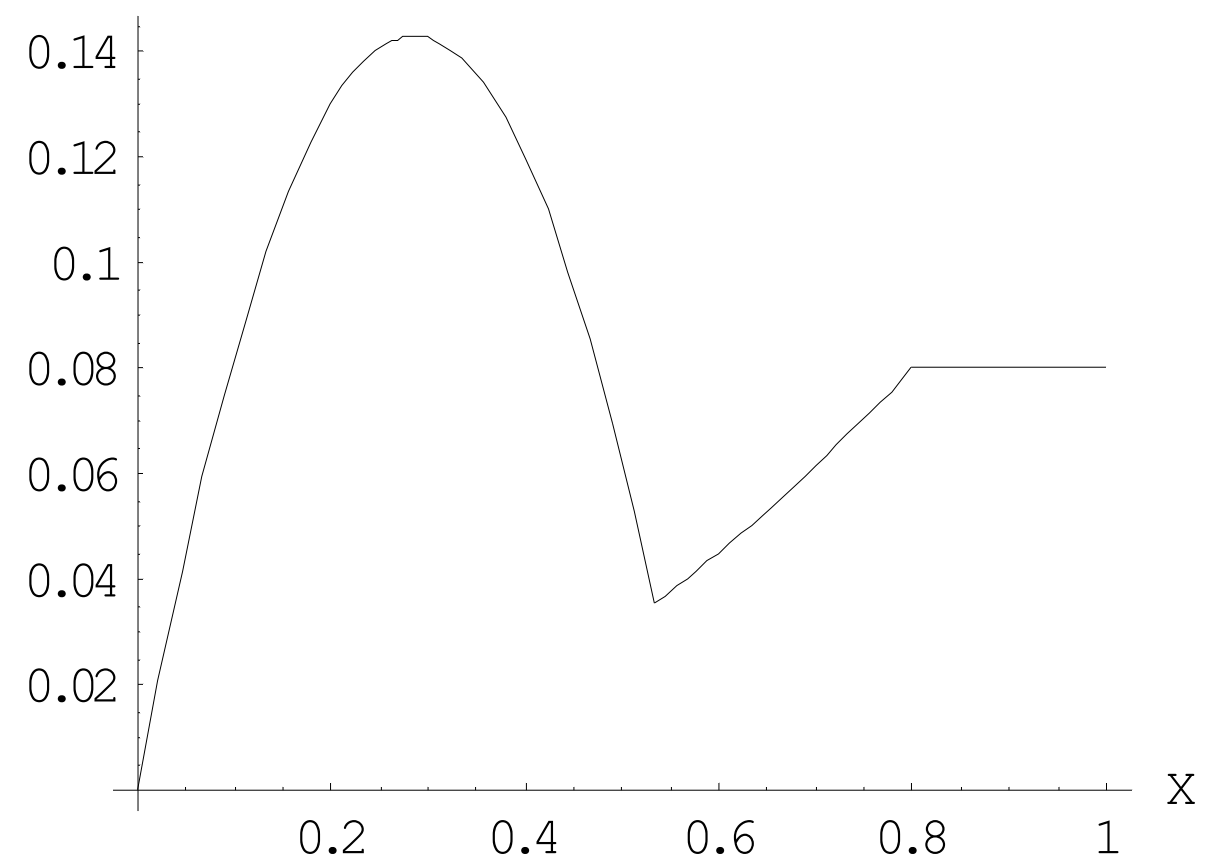

Figure 3: Downstream profits. 
Next we study the profitability of the mergers of retailers. In this setting, mergers have two effects on profitability: the typical anticompetitive effect and the effect on wholesale prices. Since Salant et al. (1983) we know that, in a Cournot setting, the anticompetitive effect may reduce the profits of merging partners because nonmerging firms increase their production. To guarantee that this is not the case in our calculations, we restrict attention to the merger to monopoly, where the reduction of competition increases for sure the profits of merging firms. Furthermore, this allows us to use the results obtained so far regarding the industry profits with $n$ firms (see equation (1))

In the premerger situation we have $n$ retailers operating in the market. Then, all retailers merge. We want to study the profitability of this merger. A merger is said to be profitable if it increases the profits of the downstream firms ( $\left.\Pi^{D}(1)>\Pi^{D}(n)\right)$.

As far as wholesale prices are concerned, proposition 4 tells us that the merger to monopoly will increase wholesale prices when $X<\frac{a n}{2 n+1}$ (it corresponds to the cutoff point identified in Proposition 4 when $n_{1}=1$ and $n_{2}=n$ ). It will decrease wholesale prices if $\frac{a n}{2 n+1}<X<\frac{a n}{n+1}$ and it will not affect wholesale prices if $X \geq \frac{a n}{n+1}$. In this last case, we are in the unconstrained case and the wholesale price is $\frac{a}{2}$ both for the case of $n$ retailers and for the case of monopoly.

As far as the competition effect is concerned, the merger has the positive effect of reducing output (increasing retail prices) only if capacity is high $(X>$ $\frac{a}{2}$ ), because otherwise firms sell up to capacity in any market structure.

Combining the results on competition and wholesale prices we obtain four different regions:

- If $X \geq \frac{a n}{n+1}$, the merger is profitable, because it reduces competition.

-If $\frac{a}{2}<X<\frac{a n}{n+1}$, the merger is profitable, because it reduces both competition and wholesale prices.

- If $\frac{a n}{2 n+1}<X \leq \frac{a}{2}$, the merger is profitable, because it reduces wholesale prices and it does not affect sales.

-If $0<X \leq \frac{a n}{2 n+1}$, the merger is not profitable, because it increases wholesale prices and it does not affect sales.

Next proposition summarizes the results on profitability.

Proposition 5 With multiple upstream firms, the merger to monopoly of downstream firms is not profitable if $0<X \leq \frac{a n}{2 n+1}$ and profitable otherwise.

It is very easy to find the counterpart of proposition 5 for the case where producers have merged. Given the wholesale prices identified in Proposition 1 
we can write down the downstream industry profits for this case:

$$
\Pi^{M}(n)=\left\{\begin{array}{cc}
\frac{X^{2}}{2 n} & \text { if } 0 \leq X \leq \frac{a n}{n+1} \\
\frac{a^{2} n}{2(n+1)^{2}} & \text { otherwise }
\end{array} .\right.
$$

In this case, downstream industry profits are always decreasing in $n$. Therefore, $\Pi^{D}(1)>\Pi^{D}(n)$ holds for any level of capacity. Next proposition summarizes.

Proposition 6 With monopoly upstream, the merger to monopoly of downstream firms is always profitable.

Putting together propositions 5 and 6 , we obtain that the merger of the upstream firms stimulates the merger of downstream firms when $0<X \leq \frac{a n}{2 n+1}$. This is coherent with the empirical fact that parallel processes of consolidation in both upstream and downstream sectors are observed. ("We thus have evidence for all the studied countries, except the Netherlands, that merger activity in manufacturing has led to merger activity in retailing" (Kastrinaki and Stoneman (2011) p. 476).

\section{Conclusion}

We have considered two independent goods that are sold to consumers through retailers. The units of both goods sold by retailers cannot exceed the industry selling capacity that it is distributed symmetrically among retailers. We consider possible different market structures. As far as the upstream sector is concerned, we consider both the possibility that the two goods are produced by the same firm (upstream monopoly) and the possibility that they are produced by different firms (multiple upstream firms). As far as the downstream sector is concerned, we consider the case of a general number of symmetric retailers i.e. all retailers have the same selling capacity.

The objective of this paper has been to test the effect of retailers size on the linear wholesale prices set by producers. The reference point is the countervailing power theory that implies a negative correlation between wholesale prices and retailers size. This is what we obtain in this paper except when we have multiple upstream firms and the selling capacity is small. This also explains that the merger of all retailers is always profitable except when we have multiple upstream firms and selling capacity is low, because then the merger increases wholesale prices.

It is important to check the validity of the countervailing power theory in order to be able to assess correctly the effect of increases in concentration in the downstream market on the overall industry. Our contribution has shed some light on this issue for the case where the selling capacity of retailers is low with respect to market demand. The type of capacity constraints, first introduced in this paper, may be used fruitfully in future papers to discuss related issues. 


\section{Appendix}

\subsection{Appendix 1}

- The upstream monopolist will not choose the input prices in the interior of Region 2i. In this Region we have:

$$
\frac{a-w_{1}}{n+1}+\frac{a-w_{2}}{n+1}>\frac{X}{n}
$$

She can increase the profits by raising slightly the input prices: she sells the same but a higher price.

In Region 2ii, we have $\frac{a-w_{1}}{n+1}>\frac{X}{n}$, then again it can increase slightly input prices and increase profits, because it sells the same but at a higher price. The same argument applies to Region 2iii

-The upstream monopolist will not choose input prices in the interior of Region 1. We have

$$
\begin{aligned}
\frac{a-w_{1}}{n+1}+\frac{a-w_{2}}{n+1} & <\frac{X}{n}<\frac{a}{n+1} \\
a & <w_{1}+w_{2}
\end{aligned}
$$

So the maximization program of the monopolist is

$$
\underset{w_{1}, w_{2}}{\operatorname{Max}} \Pi=n w_{1}\left(\frac{a-w_{1}}{n+1}\right)+n w_{2}\left(\frac{a-w_{2}}{n+1}\right)
$$

Then, we have

$$
\frac{\partial \Pi}{\partial w_{1}}+\frac{\partial \Pi}{\partial w_{2}}=\left(\frac{2 n}{n+1}\right)\left(a-w_{1}-w_{2}\right)<0
$$

Given the restriction, the two FOCs can not be satisfied. Therefore there are no input prices in Region 1 that maximize profits.

- So the optimal prices should be in the frontier between Region $2 \mathrm{i}$ and Region 1. Then we have:

$$
\begin{aligned}
\frac{a-w_{1}}{n+1}+\frac{a-w_{2}}{n+1} & =\frac{X}{n} \\
w_{2}\left(w_{1}\right) & =2 a-w_{1}-X\left(\frac{n+1}{n}\right)
\end{aligned}
$$

Profits can be written as a function of $w_{1}$ only:

$$
\Pi=n w_{1}\left(\frac{a-w_{1}}{n+1}\right)+n w_{2}\left(w_{1}\right)\left(\frac{a-w_{2}\left(w_{1}\right)}{n+1}\right)
$$

It is maximized in $w_{1}=a-\frac{(n+1) X}{2 n}$ and $w_{2}\left(a-\frac{(n+1) X}{2}\right)=a-\frac{(n+1) X}{2 n}$. Those are the optimal wholesale prices 


\subsection{Appendix2}

The best response of supplier 1 is given by.

$$
\begin{aligned}
& \text { If } 0<X \leq \frac{a n}{3(n+1)} \\
& B_{1}\left(w_{2}\right)\left\{\begin{array}{l}
\frac{n w_{2}+(n+1) X}{2 n} \\
w_{2}-\frac{(n+1) X}{n}
\end{array}\right. \\
& \text { if } \quad 0 \leq w_{2} \leq \frac{3(n+1) X}{n} \\
& \text { if } \quad \frac{3(n+1) X}{n}<w_{2} \leq a \\
& \text { If } \frac{a n}{3(n+1)} \leq X \leq \frac{a n}{2(n+1)} \\
& B_{1}\left(w_{2}\right)=\left\{\begin{array}{l}
\frac{n w_{2}+(n+1) X}{2 n} \\
2 a-\frac{(n+1) X}{n}-w_{2}
\end{array}\right. \\
& \text { if } \quad 0 \leq w_{2} \leq \frac{4 a}{3}-\frac{(n+1) X}{n} \\
& \text { if } \quad \frac{4 a}{3}-\frac{(n+1) X}{n}<w_{2} \leq a \\
& \text { If } \frac{a n}{2(n+1)} \leq X<\frac{a n}{n+1} \\
& B_{1}\left(w_{2}\right)=\left\{\begin{array}{ccc}
\frac{n w_{2}+(n+1) X}{2 n} & \text { if } \quad 0 \leq w_{2} \leq \frac{4 a}{3}-\frac{(n+1) X}{n} \\
2 a-\frac{(n+1) X}{n}-w_{2} & \text { if } \quad \frac{4 a}{3}-\frac{(n+1) X}{n}<w_{2} \leq \frac{3 a}{2}-\frac{(n+1) X}{n} \\
\frac{a}{2} & \text { if } \quad \frac{3 a}{2}-\frac{(n+1) X}{n}<w_{2} \leq a
\end{array}\right.
\end{aligned}
$$

Given $X$, this reaction function crosses the 45 degree line only once. This crossing point determines the equilibrium in wholesale prices that is stated in proposition 3. The equilibrium is symmetric and it will be in Region $2 \mathrm{i}$ or in the frontier between Region $2 \mathrm{i}$ and Region 1 . The portion of the reaction function in Region $2 \mathrm{i}$ is: $\frac{n w_{2}+(n+1) X}{2 n}$ and the one that lies in the frontier of Region $2 \mathrm{i}$ and Region 1 is : $2 a-\frac{(n+1) X}{n}-w_{2}$. The former expression crosses the 45 degree line in $\frac{(n+1) X}{n}$ and the latter expression crosses the 45 degree line in $a-\frac{(n+1) X}{2 n}$. It will be the equilibrium the one that first crosses the 45 degree line. The equilibrium will be $\frac{(n+1) X}{n}$ if $\frac{(n+1) X}{n}<a-\frac{(n+1) X}{2 n}$ (This holds if $\left.X<\frac{2 a n}{3(n+1)}\right)$ and $a-\frac{(n+1)^{n} X}{2 n}$ otherwise. 


\subsection{Appendix 3}

Functions $a-\frac{\left(n_{1}+1\right) X}{2 n_{1}}$ and $\frac{\left(n_{2}+1\right) X}{n_{2}}$ cross in $\tilde{X}=\frac{2 a n_{1} n_{2}}{2 n_{1}+n_{2}+3 n_{1} n_{2}}$. We have that $\frac{2 a n_{1}}{3\left(n_{1}+1\right)}<\widetilde{X}<\frac{a n_{1}}{n_{1}+1}$. This implies that the wholesale price is higher with $n_{1}$ than with $n_{2}$ if $0<X<\tilde{X}$ and lower if $\tilde{X}<X<\frac{a n_{2}}{n_{2}+1}$.

\section{References}

Chipty, T. and C.M. Snyder (1999) "The role of outlet size in bilateral bargaining: a study of the cable television industry". Review of Economics and Statistics 81, pp. 326-340.

Dobson, P. and M. Waterson (1997). 'Countervailing power and consumer prices', Economic Journal, vol. 107, pp. 418-30.

Erlebacher, S.J. (2000) "Optimal and heuristic solutions for the multi-item newsvendor problem with a single capacity constraint" POMS Series in Technology and Operations Management, Vol. 9 pp. 303-318

Gabrielsen, T.S. and L. Sorgard (1999) "Discount chains and brand policy" Scandinavian Journal of Economics 101 (1), pp.127-142.

Galbraith, J. K. 1952. American Capitalism: The Concept of Countervailing Power. Boston, MA: Houghton Mifflin.

Gaudin, G. (2018) "Vertical Bargaining and Retail Competition: What Drives Countervailing Power?" Economic Journal, Vol.

128(614), pp. 2380-2413.

Horn, H. , and A. Wolinsky. (1988). "Bilateral Monopolies and Incentives for Merger." RAND Journal of Economics 19 (3), pp. 408-19.

Inderst, R and G. Shaffer (2007) "Retail mergers, buyer power and product variety" The Economic Journal 117, pp. 45-67.

Inderst, R. and C.Wey (2011) "Countervailing Power and Dynamic Efficiency" Journal of the European Economic Association 9(4), pp. 702-720.

Iozzi,A. and T. Valetti (2014) "Vertical bargaining and countervailing power" American Economic Journal: Microeconomics, 6(3), pp. 106-135.

Kastrinaki, Z. and P. Stoneman (2011) "Merger Patterns in the European Food Supply Chain", International Journal of the Economics of Business 18:3, pp. 463-487.

Katz, M.L. (1987) "The welfare effects of third-degree price discrimination in intermediate good markets" American Economic Review 77 (1), pp. 154-167.

Milliou, C. and J. Sandonís (2018) "Manufacturer mergers and product variety in vertically related markets", Journal of Industry, Competition and Trade 18.1, pp. 1-24.

Moner-Colonques, R. (2006) "The tradeoffs between retail service and exclusivity in distribution: Welfare and policy implications" International Review of Law and Economics 26, pp. 241-261. 
Motta, M. (2006) Competition policy: theory and practice. Cambridge University Press.

O'Brien, D.P. and G. Shaffer (1997) "Nonlinear supply contracts, exclusive dealing and equilibrium market foreclosure" Journal of Economics \& Management Strategy 6(4), pp. 755-785.

Salant, S., S. Switzer and R.J. Reynolds (1983) "Losses from horizontal merger: the effects of an exogenous change in industry structure on CournotNash equilibrium" Quarterly Journal of Economics 98, pp185-199.

Shaffer, G. (1991) "Capturing strategic rent: Full-Line Forcing, brand discounts, aggregate rebates and maximum resale price maintenance" The Journal of Industrial Economics Vol. 39. No 5, pp- 557-575.

Snyder, C.M. (1996) "A dynamic theory of countervailing power" Rand Journal of Economics 20, pp.747-69.

Tyagi, R.K. (1999). 'On the effects of downstream entry', Management Science, vol. 45(1), pp. 59-73.

Von Ungern-Sternberg, T. (1996). 'Countervailing power revisited', International Journal of Industrial Organization vol. 14, pp. 507-20. 